\title{
Armazenamento de sementes de sorgo submetidas a diferentes graus de umidade de colheita
}

\section{Storage of sorghum seeds harvested with different moisture levels}

\author{
Glaucia de Fátima Moreira Vieira e Souza ${ }^{1}$; Carlos Machado dos Santos ${ }^{2 *}$; \\ Denise Garcia de Santana²; Adílio de Sá Júnior ${ }^{3}$
}

\begin{abstract}
Resumo
Sementes híbridas de sorgo foram colhidas com diferentes graus de umidade e armazenadas em ambiente climatizado por 28 meses, em Uberlândia-MG. Utilizaram-se sementes obtidas de um experimento conduzido em campo de produção comercial da Monsanto do Brasil Ltda., safra 2002/2003. As amostras das parcelas foram acondicionadas em sacos de papel multifoliados e armazenadas em armazém climatizado (temperatura de $10^{\circ} \mathrm{C}$ e umidade relativa de $50 \%$ ) na unidade de beneficiamento da Monsanto do Brasil Ltda. O delineamento experimental foi o de blocos casualizados com parcelas subdivididas no tempo. Na parcela os tratamentos constituíram-se por amostras de sementes colhidas com quatro graus de umidade $(20 \%, 18 \%, 14 \%$ e $11 \%)$, e nas subparcelas avaliou-se quatro tempos de armazenamento (início, 10, 22 e 28 meses). Estudou-se a umidade das sementes durante o armazenamento e as alterações na qualidade fisiológica das sementes, utilizando-se os testes de germinação e de frio. Concluiu-se que: a) o grau de umidade das sementes de sorgo aumentou com o do tempo de armazenamento; b) a qualidade fisiológica das sementes reduziu com o aumento da umidade programada para colheita e do tempo de armazenamento, porém, a porcentagem de germinação se manteve dentro dos padrões para comercialização até aos 28 meses.
\end{abstract}

Palavras-chave: Sorghum bicolor, armazém climatizado

\begin{abstract}
The aim of this research work was to study the effect of storage in a climatized environment on the physiologic quality of hybrid of sorghum seeds harvested with different moisture contents and submitted to storage, in Uberlândia-MG. The seeds used were collected in a commercial seed production field of Monsanto Brasil Ltd., in the cropping season 2002/2003. The samples were placed in multi-layer paper bags, stored in a climatized warehouse at the processing unit of Monsanto Brasil Ltd. The experimental design was randomized blocks with split plots on time. The experiment had seed samples harvested with four moisture contents $(20 \%, 18 \%, 14 \%$ and $11 \%)$ and four storage times (beginning of storage, 10, 22 and 28 months). The changes on seed physiologic quality were evaluated by germination test (normal or abnormal seedlings), cold test (vigour). Also, the moisture content of the seeds was analyzed during storage. From the results, it can be concluded that: a) as harvest proceeded with greater moisture contents, the physiologic quality of these seeds decreased; b) seed physiologic quality decreased significantly; however, the germination percentage remained within the commercialization standard until 28 months. Key words: Sorghum bicolor, climatized environment.
\end{abstract}

1 Engenheira Agrônoma, Doutoranda do curso de Pós-Graduação em Engenharia Mecânica da Universidade Federal de Uberlândia (UFU). E-mail: glaucia.souza@gmail.com.

2 Professor Dr. e Professora Dra. ., respectivamente, do Instituto de Ciências Agrárias (ICIAG) / UFU, Uberlândia-MG. E-mail: cmsantos@umuarama.ufu.br,dgsantana@umuarama.ufu.br.

3 Técnico do Laboratório de Análise de Sementes (LASEM), ICIAG/UFU, Uberlândia-MG; Discente do curso de Agronomia da UNIPAC/ Uberlândia-MG. E-mail: adilio.junior@yahoo.com.br

* Autor para correspondência 


\section{Introdução}

O sorgo [Sorghum bicolor (L.) Moench] é uma planta anual, pertencente à família Gramineae, com grãos de constituição química bastante semelhante à do milho, podendo assim ser utilizado em complementação ao milho em rações de aves, bovinos e suínos. Como principal característica apresenta maior resistência à seca que o milho.

Tem sido verificada grande expansão do cultivo do sorgo, em algumas regiões em plantios de sucessão, com destaque para os estados de São Paulo, Goiás, Mato Grosso, Mato Grosso do Sul e a região do Triângulo Mineiro, onde se concentra aproximadamente $85 \%$ do sorgo granífero plantado no Brasil (EMPRESA BRASILEIRA DE PESQUISA AGROPECUÁRIA, 2007).

Dentre as cultivares disponíveis, têm predominado o uso de híbridos simples para plantios em sucessão, por esses materiais apresentarem ampla adaptabilidade e estabilidade de produção, mas expressam sua produtividade máxima apenas na primeira geração, sendo necessária aquisição de sementes todos os anos. Para isso a indústria de sementes oferece condições para o atendimento da demanda das várias regiões de cultivo de sorgo. As opções possibilitam ao produtor a escolha de alternativas adequadas ao sistema de produção a ser adotado (SANTOS, 2003). A indústria de sementes oferece condições para o atendimento da demanda das várias regiões de cultivo de sorgo onde na safra de 2007/2008 foram disponibilizados para comercialização 26 híbridos oriundos de empresas dos setores público e privado, entre eles o híbrido simples AG 1018 (SANTOS; TARDIN, 2007).

$\mathrm{O}$ ambiente no campo tem um efeito profundo sobre a qualidade fisiológica das sementes (DELOUCHE, 2002). De acordo com Tillmann, Santos e Peters (1991), dentre os vários fatores que exercem influência tanto na qualidade quanto na quantidade das sementes, um dos mais importantes é o momento da colheita. O grau de maturação das sementes no momento da colheita afeta sua qualidade inicial, sendo que as colhidas antes ou após a maturidade fisiológica apresentam um menor potencial de armazenamento (CARVALHO; NAKAGAWA, 2000).

A semente é um dos insumos mais importantes na agricultura moderna e dentre as várias etapas pelas quais as sementes passam após colheita, o armazenamento constitui etapa obrigatória de um programa de produção assumindo importante papel, principalmente no Brasil devido às condições climáticas tropicais e subtropicais. É nessa fase que os produtores necessitam ter grandes cuidados visando a preservação da qualidade, diminuindo a velocidade do processo deteriorativo e o problema de descarte dos lotes (MACEDO; GROTH; SOAVE, 1998).

No que se refere às condições de armazenamento, a umidade e a temperatura são os fatores que mais afetam a manutenção da qualidade das sementes e a sua condução de forma regular e eficiente refletirá na viabilidade das sementes. As melhores condições para manutenção de qualidade das sementes são baixa umidade relativa do ar e baixa temperatura, pelo fato de manterem o embrião em baixa atividade metabólica (CARVALHO; NAKAGAWA, 2000; DHINGRA, 1985).

Literatura sobre o armazenamento de sementes de sorgo por períodos mais longos é escassa no Brasil, e essas informações são importantes quando se deseja armazenar as sementes de uma safra para outra. Assim, o presente trabalho teve como objetivo estudar a qualidade das sementes de sorgo, AG 1018, submetidas a diferentes graus de umidade de colheita durante armazenamento em ambiente controlado.

\section{Material e métodos}

Foram utilizadas sementes de sorgo, hibrido AG 1018, obtidas de acordo com trabalho de pesquisa conduzido por Olivato (2004) em campo de produção de sementes comercias da empresa 
Monsanto do Brasil Ltda, em Uberlândia-MG, safra 2002/2003. A colheita das sementes foi realizada com diferentes graus de umidade. As amostras foram secadas até as sementes atingirem $11 \%$ de umidade. As amostras foram acondicionadas em sacos de papel multifoliados armazenadas em armazém climatizado (temperatura de $10{ }^{\circ} \mathrm{C}$ e umidade relativa de $50 \%$ ), da unidade de beneficiamento da Monsanto do Brasil Ltda, em Uberlândia-MG. As análises para avaliação das alterações na qualidade das sementes foram realizadas nos Laboratórios de Análise de Sementes da Monsanto do Brasil Ltda. e da Universidade Federal de Uberlândia, ambos em Uberlândia - MG.

Os tratamentos foram constituídos pelas amostras de sementes colhidas com quatro graus de umidade $(20 \%, 18 \%, 14 \%$ e $11 \%)$ durante quatro tempos de armazenamento (início do armazenamento, 10, 22 e 28 meses). O delineamento experimental foi o de blocos casualizados com parcelas subdivididas no tempo, com quatro repetições. Na parcela estudouse o fatorial, e nas subparcelas os tempos de armazenamento.

As avaliações das alterações na qualidade das sementes durante o armazenamento, foram realizadas nos meses de setembro de 2003 (início do armazenamento), julho de 2004 (10 meses), julho de 2005 (22 meses) e janeiro de 2006 (28 meses). Nos laboratórios, foram conduzidas as determinações do grau de umidade e os testes de germinação e de frio (vigor).

A determinação do grau de umidade foi realizada utilizando se método expedito ${ }^{4}$, conforme prescrição das Regras para Análise de Sementes RAS (BRASIL, 1992).

Depois de realizadas duas leituras por amostra fez-se a média, respeitando-se uma diferença máxima de $0,5 \%$ entre as determinações.

\footnotetext{
4 Equipamento Multi Grain, comercializado pela ETEC/ Aparelhos - Medição.
}

O teste de germinação foi realizado utilizandose 200 sementes por parcela, distribuídas em quatro sub-amostras de 50 sementes. As sementes foram semeadas em substrato de papel umedecidos com água deionizada com quatro horas de antecedência, confeccionando-se os rolos. Para cada sub-amostra de 50 sementes foram utilizadas duas folhas de substrato umedecido. A quantidade de água, em mililitros, utilizada no umedecimento do papel, consistia de duas e meia vezes o peso do papel seco em gramas. Após a montagem dos rolos, estes foram colocados em gabinetes e levados para uma sala de germinação, com temperatura alternada de 25 $30^{\circ} \mathrm{C}$. As avaliações foram feitas aos cinco dias após o início do teste, determinando-se a porcentagem de plântulas normais e anormais, conforme descrição das Regras para análise de sementes (BRASIL, 1992).

O teste de frio (vigor) foi realizado utilizandose 200 sementes por parcela, distribuídas em duas sub-amostras de 100 sementes em bandejas de plástico $(50 \mathrm{~cm}$ de comprimento x $30 \mathrm{~cm}$ de largura x $2 \mathrm{~cm}$ de altura), onde cada bandeja, continha subamostras de 2 parcelas. As sementes foram semeadas sobre uma camada de $1,5 \mathrm{~cm}$ de substrato $(1,5 \mathrm{~L})$ e cobertas com outra camada de substrato com a mesma espessura. As bandejas foram irrigadas, com ajuda de um regador, com $600 \mathrm{~mL}$ de água. Após, as bandejas foram colocadas em gabinetes, sendo levados à câmara fria regulada à temperatura de $10^{\circ} \mathrm{C} \pm 2^{\circ} \mathrm{C}$, onde permaneceram por sete dias. Após esse período os gabinetes foram removidos da câmara fria e levados para a sala de germinação, com temperatura de $26^{\circ} \mathrm{C}$, onde permaneceram durante cinco dias, procedendo-se em seguida a avaliação do número de plântulas emersas. Foi realizada a média da avaliação das duas sub-amostras sendo o resultado dado em porcentagem.

Após a obtenção dos dados, foram efetuadas as análises de variância, para todas as características avaliadas. Quando houve efeito significativo 
isolado dos fatores, realizou-se a análise de regressão para cada um deles. Os dados estatísticos foram analisados pelo software SANEST (ZONTA; MACHADO, 1989).

\section{Resultados e Discussão}

A umidade das sementes foi influenciada apenas pelo tempo de armazenamento.

Observou-se um aumento linear da umidade das sementescomoaumentodotempodearmazenamento, onde passou de aproximadamente $10 \%$ para $12 \%$ ao final dos 28 meses, que está representado na Figura
1. Esse aumento no grau de umidade ocorre devido à higroscopicidade das sementes, que determina sua capacidade de estar em permanente troca de água com a atmosfera que a rodeia. A predominância do fluxo de água é determinado pelo gradiente de potencial hídrico entre as sementes e o ar atmosférico. Quando a diferença de potencial é nula, cessa o processo de transferência de água e as sementes entram em equilíbrio higroscópico com o meio (SILVA, 1986) que proporciona um processo dinâmico de troca de umidade com o ar circundante, até que seja atingido o ponto de equilíbrio higroscópico (CARVALHO, 1994).

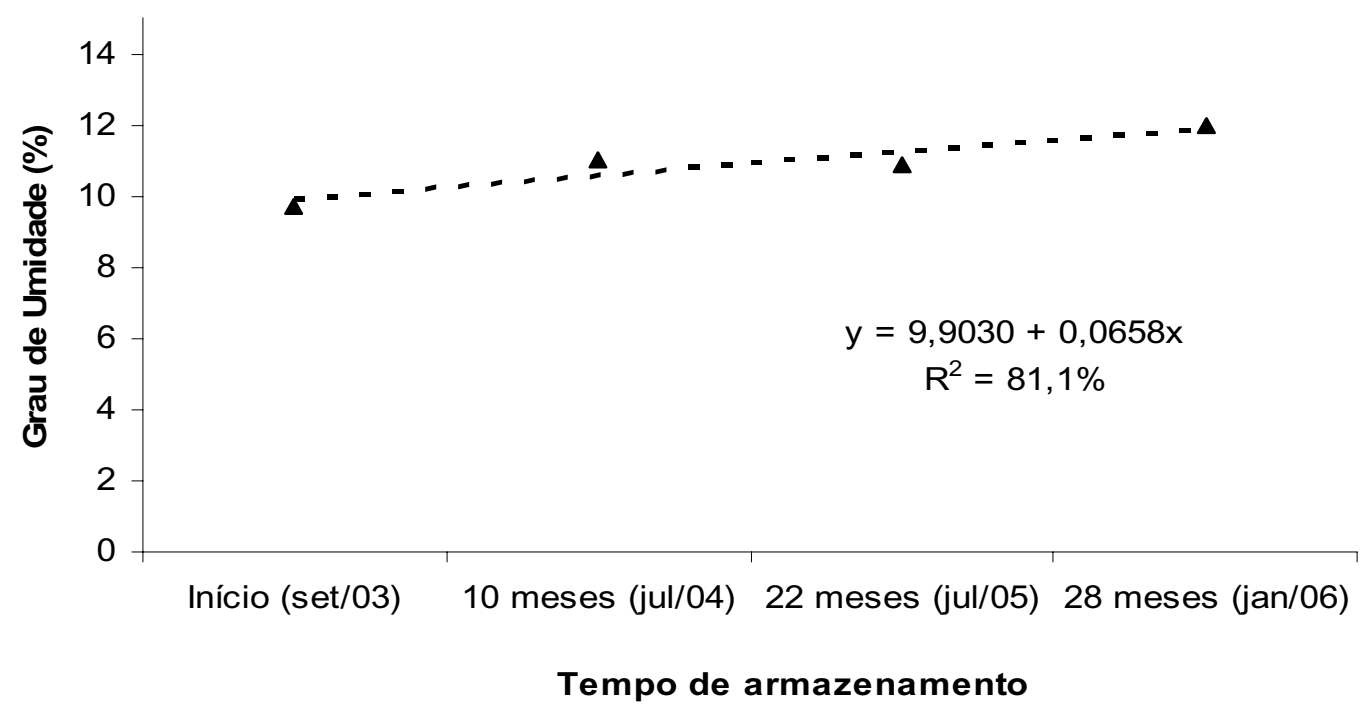

Figura 1. Modelo de regressão para o grau de umidade, em função dos diferentes tempos de armazenamento, das sementes de sorgo, AG 1018, colhidas com diferentes graus de umidade e armazenadas em ambiente climatizado. Uberlândia (MG), 2005.

Para as variáveis testes de germinação e frio, a umidade programada para colheita e o tempo de armazenamento foram significativos, indicando que esses fatores alteram as variáveis citadas.

Na Figura 2, observa-se que o maior número médio de plântulas normais do teste de germinação foi obtido na umidade de $12,5 \%$, correspondente a $88 \%$, a partir daí esse valor diminuiu, chegando a $81 \%$ de plântulas normais na umidade programada para colheita de $20 \%$. Verifica-se também que o número médio de plântulas emersas (vigor) obtidas no teste de frio caiu linearmente, onde a cada $1 \%$ de incremento na umidade programada para colheita houve um decréscimo de aproximadamente 1\% $(0,9711 \%)$, atingindo $68 \%$ na UPC de $20 \%$. É possível visualizar também que antes mesmo da germinação ser afetada, o vigor das sementes reduziu significativamente. Verifica-se que à medida que se 
aumentou a umidade programada para colheita, tanto a germinação quanto o vigor das sementes diminuiu, sendo mais acentuada a queda no vigor em relação à germinação. Isso provavelmente ocorre pelo fato do teste de vigor detectar transformações degenerativas mais suaves, não reveladas pelo teste de germinação o qual é realizado em condições ideais (POPINIGIS,
1985). Assim a importância de se utilizar em conjunto resultados de vários testes para a avaliação do potencial fisiológico das sementes se torna evidente (MARCOS FILHO, 1999), principalmente quando se quer ter um indicativo do potencial de armazenamento das sementes. O teste de frio, com ou sem solo, é um dos mais sensíveis na detecção de diferenças de vigor (CARVALHO, 1986).

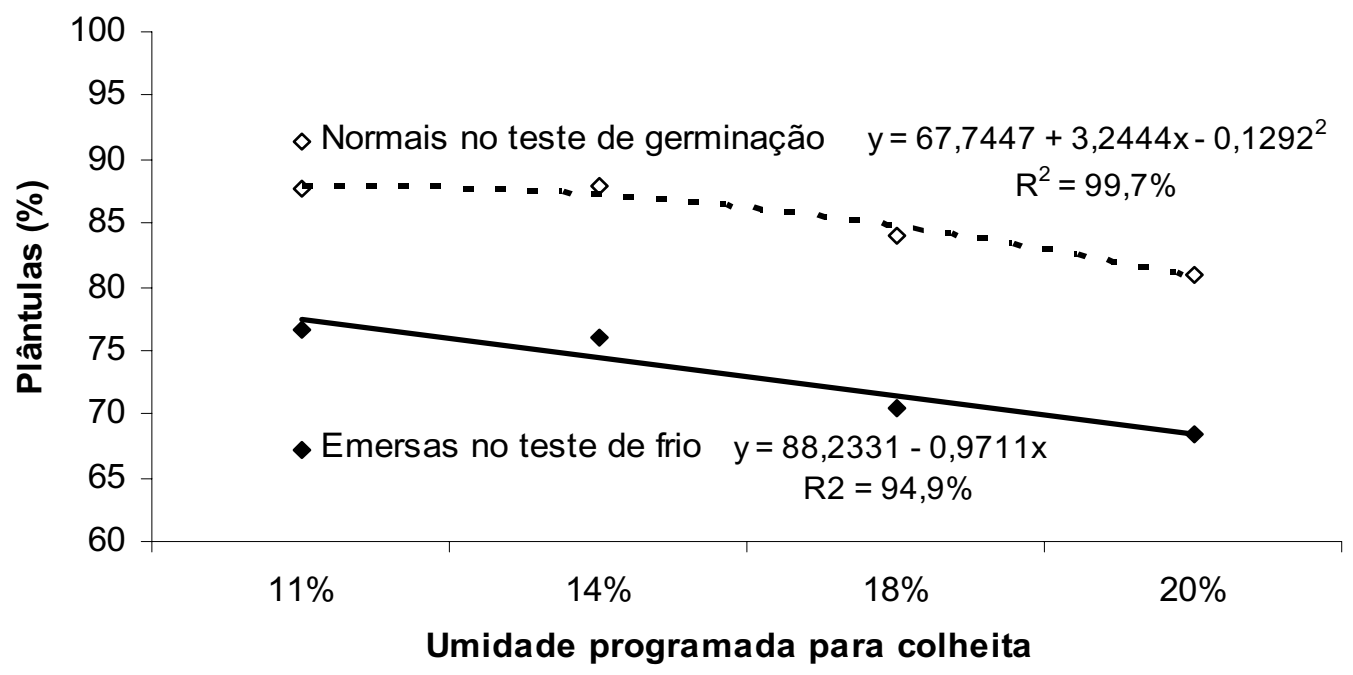

Figura 2. Modelos de regressão para porcentagem de plântulas normais do teste de germinação e plântulas emersas do teste de frio, em função das diferentes umidades programadas para colheita de sementes de sorgo, AG 1018. Uberlândia (MG), 2005.

Essa diminuição tanto da germinação quanto do vigor à medida que se aumentou a umidade de colheita pode ser devido principalmente ao processo deteriorativo, que está estreitamente associado ao grau de umidade das sementes, onde o acréscimo da umidade pode promover uma aceleração na deterioração. As características termodinâmicas das sementes são distorcidas quando a hidratação chega a graus intermediários (7,5 a 20\%), nesta condição atividades oxidativas se relacionam às taxas de deterioração, onde vários constituintes celulares estão susceptíveis à degradação (MARCOS FILHO, 2005). Outro fator seria o grau de injúrias mecânicas que pode aumentar com a umidade da semente. Oliveira et al. (1997) em experimento com a cultura do milho constataram que sementes colhidas mecanicamente com $18 \%$ de umidade alcançaram percentuais de germinação e vigor maiores em relação às sementes colhidas com $28 \%$ de umidade (pelo teste de envelhecimento acelerado). Em sementes colhidas manualmente estas diferenças não foram detectadas, evidenciando que não houve deterioração, desse modo os autores concluíram que esse fato ocorreu provavelmente por uma maior incidência de danos mecânicos nas sementes mais úmidas.

Na Figura 3, são apresentados os modelos de regressão para a porcentagem de plântulas normais do teste de germinação e de plântulas emersas do teste de frio, em função dos diferentes tempos de armazenamento das sementes de sorgo do híbrido AG 1018. Verifica-se que número médio de plântulas normais do teste de germinação caiu linearmente 
com o aumento do tempo de armazenamento, partindo de aproximadamente $88 \%$ e chegando a $81 \%$ aos 28 meses, a uma taxa de $0,212 \%$ para cada mês de acréscimo no tempo de armazenamento. É importante salientar que esse valor está dentro do valor estabelecido pelas normas e padrões para comercialização de sementes de sorgo, onde o percentual mínimo aceito para germinação é de $80 \%$ (ASSOCIAÇÃO PAULISTA DE PRODUTORES DE SEMENTES E MUDAS, 2005). O valor de $81 \%$ supera o obtido por Maeda et al. (1987), que foi de $71 \%$ para sementes de sorgo armazenadas por 28 meses a $20^{\circ} \mathrm{C}$ de temperatura e $55 \%$ de umidade relativa. Isso ocorreu provavelmente devido a menor qualidade inicial das sementes utilizadas por Maeda et al. (1987), que apresentavam germinação inicial de $80 \%$. Andrade et al. (1994), em trabalho com 18 cultivares de sorgo, em condições de ambiente não controlado, detectaram uma queda bastante acentuada na germinação dessas sementes após 18 meses de armazenamento, reforçando a importância do controle da temperatura e da umidade relativa do ar para uma maior conservação do potencial de armazenamento das sementes de sorgo. Verifica-se também que o vigor (plântulas emersas do teste de frio), seguiu a mesma tendência da variável anterior, decrescendo linearmente com o aumento do tempo de armazenamento, partindo de aproximadamente $78 \%$ e alcançando 68,5\% após 28 meses de armazenamento, a uma taxa de decréscimo de $0,33 \%$ a cada mês de incremento no tempo de armazenamento. Nesse caso também houve diminuição da germinação e do vigor das sementes com o aumento do tempo de armazenamento, concordando com Martins Netto et al. (1998), que verificaram que já após 12 meses de armazenamento em câmara fria $\left(10^{\circ} \mathrm{C}\right.$ de temperatura e $30 \%$ de umidade relativa), sementes de sorgo tratadas com fungicida, tiveram seu vigor afetado pelo armazenamento.

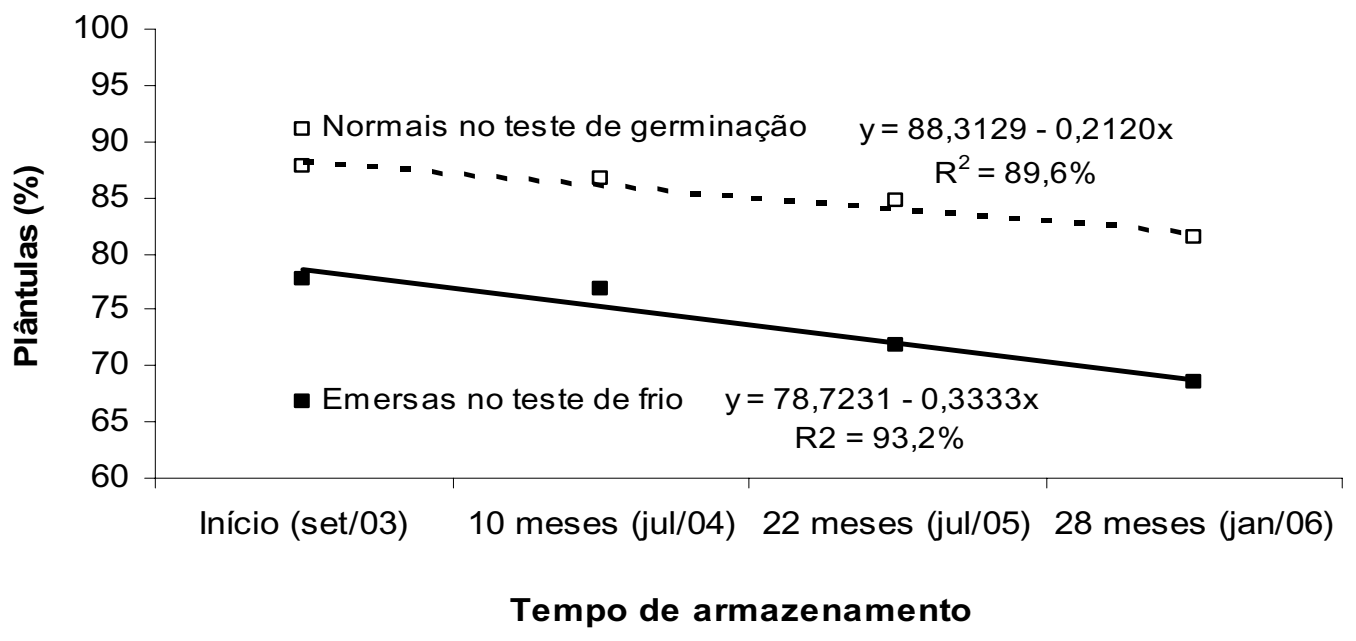

Figura 3. Modelos de regressão para porcentagem de plântulas normais do teste de germinação e plântulas emersas do teste de frio, em função dos diferentes tempos de armazenamento de sementes de sorgo, AG 1018. Uberlândia (MG), 2005 . 
O processo deteriorativo, teoricamente, se inicia na maturação fisiológica, no entanto a deterioração é detectada com maior freqüência durante o armazenamento. O declínio do potencial fisiológico com o transcurso do tempo não se restringe a diminuição da capacidade de germinação, mas esta vai ficando mais lenta, assim como se acentua a sensibilidade a adversidades ambientais, caracterizando a queda do vigor (MARCOS FILHO, 2005). Outro fato importante a ser lembrado é que a velocidade da deterioração está estreitamente relacionada com a umidade das sementes, como já foi citado. No presente trabalho a umidade das sementes teve um acréscimo de cerca de $2 \%$ ao longo do armazenamento, o que certamente colaborou para intensificar o processo deteriorativo.

\section{Conclusões}

Os resultados obtidos permitem concluir que:

O grau de umidade das sementes de sorgo aumentou com o tempo de armazenamento;

A qualidade fisiológica das sementes reduziu com o aumento da umidade programada para colheita e do tempo de armazenamento, porém a porcentagem de germinação se manteve dentro dos padrões para comercialização até aos 28 meses.

\section{Agradecimentos}

Ao Instituto de Ciências Agrárias (ICIAG/ UFU), ao Conselho Nacional de Desenvolvimento Científico e Tecnológico (CNPq) e a Monsanto do Brasil Ltda, pela oportunidade e apoio financeiro para realização deste trabalho; e ao revisor pela contribuição.

\section{Referências}

ANDRADE, R. V.; AZEVEDO, J. T.; BORBA, C. S.; OLIVEIRA, A. C. Testes de vigor em sementes de sorgo para predizer o armazenamento. Revista Brasileira de Sementes, Brasília, v. 16, n. 1, p. 102-106, 1994.
ASSOCIAÇÃO PAULISTA DE PRODUTORES DE SEMENTES E MUDAS - APPS. Padrões para produção e comercialização de sementes de sorgo granífero e sorgo forrageiro. Instrução Normativa $n^{\circ}$. 2, de $12 \mathrm{dez}$. 2005. Disponível em: <http://www.apps.agr.br/upload/ ax4_2212200537864000_in25-anexox-sorgo.doc $>$. Acesso em: 20 abr. 2009.

BRASIL. Ministério da Agricultura. Secretaria Nacional de Defesa e Agropecuária. Regras para análise de sementes - RAS. Brasília, DF, 1992.

CARVALHO, N. M. Vigor de sementes. In: CÍCERO, S. M.; MARCOS FILHO, J.; SILVA, W. R. (Coord.). Atualização em produção de sementes. Campinas: Fundação Cargill, 1986. p. 207-223.

CARVALHO, N. M. A secagem de sementes. Jaboticabal: FUNEP, 1994.

CARVALHO, N. M.; NAKAGAWA, J. Sementes: ciência, tecnologia e produção. 4. ed. Jaboticabal: FUNEP, 2000.

DELOUCHE, J. C. Germinação, deterioração e vigor da semente. Seed News, Pelotas, v. 6, n. 6, nov./dez. 2002. Disponível em: <http: www.seednews.inf.br/portugues/ seed66/artigocapa66 .shtml>. Acesso em: 12 fev. 2004.

DHINGRA,O.D.Prejuízoscausadospormicroorganismos durante o armazenamento de sementes. Revista Brasileira de Sementes, Brasília, v. 7, n. 1, p. 139-145, 1985.

EMPRESA BRASILEIRA DE PESQUISA AGROPECUÁRIA - EMBRAPA. Centro Nacional de Pesquisa de Milho e Sorgo. Publicações. Sistema de Produção de Sorgo. 2007. Disponível em: <http:// www. cnpms.embrapa.br/publicacoes/sorgo/index.htm>. Acesso em: 20 abr. 2009.

MACEDO, E.; GROTH, D.; SOAVE, J. Influência da embalagem e do armazenamento na qualidade fisiológica de sementes de algodão. Revista Brasileira de Sementes, Brasília, v. 20, n. 2, p. 454-461, 1998.

MAEDA, J. A.; LAGO, A. A.; MIRANDA, L. T.; TELLA, R. Armazenamento de cultivares de milho e sorgo com resistências ambientais diferentes. Pesquisa Agropecuária Brasileira, Brasília, v. 22, n. 1, p. 1-7, 1987.

MARCOS FILHO, J. Testes de vigor: importância e utilização. In: KRZYZANOWSKI, F. C.; VIEIRA, R. D.; FRANÇA NETO, J. B. (Ed.). Vigor de sementes: conceitos e testes. Londrina: ABRATES, 1999. Cap. 1.

MARCOS FILHO, J. Fisiologia de sementes de plantas cultivadas. Piracicaba: ESALQ/USP/FEALQ, 2005.

MARTINS NETTO, D. A.; PINTO, N. F. J. A.; OLIVEIRA, A. C.; BORBA, C. S.; ANDRADE, R. V. 
Qualidade fisiológica e sanitária de sementes de sorgo danificadas. Revista Brasileira de Sementes, Brasília, v. 20, n. 2, p. 134-140, 1998.

OLIVATO, A. V. Qualidade de sementes de sorgo colhidas com diferentes graus de umidade e submetidas a periodos de espera para secagem. 2004. Dissertação (Mestrado em Agronomia/Fitotecnia) - Programa de Pós-Graduação em Agronomia, Universidade Federal de Uberlândia, Uberlândia.

OLIVEIRA, J. A.; CARVALHO, M. L. M.; VIEIRA, M. D. G. G. C.; VON PINHO, E. V. R. Efeito do método de colheita na qualidade física, fisiológica e sanitária de sementes de milho. Revista Brasileira de Sementes, Brasília, v. 19, n. 2, p. 200-206, 1997.

POPINIGIS, F. Fisiologia da semente. Brasília: AGIPLAN, 1985.

SANTOS, F. G. Cultivares de sorgo. Sete Lagoas: Ministério da Agricultura, Pecuária e Abastecimento, nov. 2003. Disponível em: <http://www.benpms.embrapa.br/ publicacoes/publica/comuni77.pdf > . Acesso em: $19 \mathrm{dez}$. 2003. (Comunicado técnico, 77).

SANTOS, F. G.; TARDIN, F. D. Cultivares. In: EMBRAPA MILHO E SORGO. Publicações, sistema de produção de sorgo. 2007. Disponível em: <http://www. cnpms.embrapa.br/publicacoes/sorgo/ cultivares.htm>. Acesso em: 20 abr. 2009.

SILVA, W. R. Secagem das sementes. In: CICERO, S. M.; MARCOS FILHO, J. Atualização em produção de sementes. Campinas: Fundação Cargill, 1986. p. 155182.

TILLMANN, M. A. A.; SANTOS, D. S. B.; PETERS, J. A. Efeito das glumas na qualidade fisiológica de sementes de sorgo sacarino durante o processo de maturação. Pesquisa Agropecuária Brasileira, Brasília, v. 26, n. 7, p. 967-973, 1991.

ZONTA, E. P.; MACHADO, A. A. SANEST: sistema de análise estatística. Campinas: Instituto Agronômico de Campinas, 1989. (Software). 